\title{
Comment on: Safety and efficacy of mirabegron: analysis of a large integrated clinical trial database of patients with overactive bladder receiving mirabegron, antimuscarinics, or placebo
}

\author{
Carmen Scandura, Giuseppe Morgia, Giorgio Ivan Russo^^ \\ Urology Section, University of Catania, Catania, Italy \\ Correspondence to: Giorgio Ivan Russo. Urology Section, University of Catania, Catania, Italy. Email: giorgioivan1987@gmail.com. \\ Comment on: Chapple CR, Cruz F, Cardozo L, et al. Safety and Efficacy of Mirabegron: Analysis of a Large Integrated Clinical Trial Database of \\ Patients with Overactive Bladder Receiving Mirabegron, Antimuscarinics, or Placebo. Eur Urol 2020;77:119-28.
}

Submitted Apr 20, 2020. Accepted for publication May 29, 2020.

doi: $10.21037 / \mathrm{tau}-20-876$

View this article at: http://dx.doi.org/10.21037/tau-20-876

Overactive bladder $(\mathrm{OAB})$ is a complex syndrome with a high prevalence. It affects all ages, but is increasingly prevalent as age increases (1-4). Many treatments have been proposed for the management of the condition, including physical therapies (magnetic stimulation, electrical stimulation, posterior percutaneous tibial nerve stimulation) (5) and intravesical injections with botulinum toxin A. Drug treatment with antimuscarinic and beta 3 agonist, however, is the therapy of choice for most patients. Antimuscarinic drugs are an early treatment option for adults with $\mathrm{OAB}$, while mirabegron has only been available since 20135 and three different systematic reviews demonstrated significant efficacy and safety in treating symptoms of $\mathrm{OAB}(6-8)$, thus expanding therapeutic possibilities for the treatment of syndrome.

In this issue of European Urology, Chapple et al. (9) summarize efficacy and safety reporting of mirabegron treatment for OAB syndrome. They pooled data from global double-blind, 12-week studies in patients with $\mathrm{OAB}$ receiving as monotherapy mirabegron, antimuscarinic (solifenacin or tolterodine) or placebo. Analyses evaluated safety, tolerability, and efficacy of each treatment and assessed differences in baseline characteristics and among subgroups: age $<65$ versus $>65$ year, age $<75$ versus $>75$ year, and men versus women. Authors found that drug- related adverse events are more frequent with antimuscarinics (AM) followed by mirabegron (MIRA) and then placebo. The incidence of dry mouth for AM group is higher (8.7\%) than that for MIRA (2.7\%) or placebo (2.4\%) group. Overall frequency of treatment-emergent adverse events (TEAEs) is $5-10 \%$ higher for older versus younger patients and 6-7\% higher for women versus men. TEAEs increased with age more in the AM than in the MIRA population and in particular constipation was seen with high frequency in AM group. Hypertension frequency is similar in treatment groups and urinary retention is $<1 \%$ in all treatment groups, age groups and in both sexes. At the end of treatment mirabegron (25 and $50 \mathrm{mg}$ ) and antimuscarinics (solifenacin $5 \mathrm{mg}$ and tolterodine $4 \mathrm{mg}$ ) were associated with a higher improvement versus placebo in the mean number of incontinence episodes $/ 24 \mathrm{~h}$, urgency episodes/24 h, volume voided/micturition and nocturia episodes. The significance of changes from baseline was, in general, greater in older patients, women and those who had received prior $\mathrm{OAB}$ medication.

How to interpret this data? The greatest incidence of dry mouth and the highest rate of constipation in older patients in antimuscarinic group does not surprise us, due to anticholinergic effects of antimuscarinics. Vazquez Roque et al. (10) showed that aging process of the enteric nervous system, pelvic floor dysfunction like a decreased rectal compliance, increased urge thresholds for defecation, decreased rest and squeeze pressures in the anal canal, anatomic abnormalities and a delayed colonic transit may be the cause of the higher incidence of constipation in

\footnotetext{
^, ORCID: 0000-0003-4687-7353.
} 
the elderly. The anticholinergic effects of antimuscarinic overlap with this precarious pathophysiology.

White et al. (11) demonstrated no evidence of increased cardiovascular risk for mirabegron or antimuscarinics over placebo in the treatment of OAB. Chapple et al. (9) shows that the incidence of hypertension is similar in all groups but it is slightly higher in older patients and in mirabegron group. As suggested by authors themselves, this may due to the fact that in mirabegron studies there where strict requirements to report hypertension and these requirements were not in historic antimuscarinics studies.

The incidence of urinary retention is low in all treatment and age groups. Kelleher et al. (12) in a systematic literature review and network meta-analysis established that mirabegron $50 \mathrm{mg}$ had a significantly lower frequency of urinary retention compared with seven active treatments (fesoterodine 4 and $8 \mathrm{mg}$, oxybutynin IR $9 \mathrm{mg}$, solifenacin $10 \mathrm{mg}$, solifenacin $5 \mathrm{mg}$ combined with mirabegron 25 or $50 \mathrm{mg}$, and trospium $60 \mathrm{mg}$ ) and no significant differences for the remaining four comparators (placebo, propiverine $20 \mathrm{mg}$, solifenacin $5 \mathrm{mg}$, and tolterodine ER $4 \mathrm{mg}$ ).

Considering the drug efficacy at the end of treatment is not unexpected that older patients in treatment groups have a greater improvement of symptoms. As suggested by authors, elderly population has a more severe symptomatology at baseline and therefore a higher opportunity for improvement.

So how to choose the best therapy for management of $\mathrm{OAB}$ ? Following the considerations of Chapple et al. (9), we may affirm that there is no the best therapy for management of $\mathrm{OAB}$, but there is the therapy that best fits patient's characteristics. The choice of the drug should consider age, sex, also, comorbidities, medications, symptoms at baseline and costs. In general mirabegron may be the best choice for elderly and in patients susceptible to constipation.

In conclusion Chapple et al. (9) reaffirm the safety, tolerability and efficacy of mirabegron, solifenacin and tolterodine in different age groups and in both sexes. Adverse events are more frequent with AM compared to MIRA and the incidence of dry mouth, due to anticholinergic effects, is higher in AM group than in the MIRA group. Future studies should consider on a large scale the safety, efficacy and adverse events in some particular categories of patients, such as patients with neurological diseases.

\section{Acknowledgments}

Funding: None.

\section{Footnote}

Provenance and Peer review: This article was commissioned by the editorial office, Translational Andrology and Urology. The article did not undergo external peer review.

Conflicts of Interest: All authors have completed the ICMJE uniform disclosure form (available at http://dx.doi. org/10.21037/tau-20-876). The authors have no conflicts of interest to declare.

Ethical Statement: The authors are accountable for all aspects of the work in ensuring that questions related to the accuracy or integrity of any part of the work are appropriately investigated and resolved.

Open Access Statement: This is an Open Access article distributed in accordance with the Creative Commons Attribution-NonCommercial-NoDerivs 4.0 International License (CC BY-NC-ND 4.0), which permits the noncommercial replication and distribution of the article with the strict proviso that no changes or edits are made and the original work is properly cited (including links to both the formal publication through the relevant DOI and the license). See: https://creativecommons.org/licenses/by-nc-nd/4.0/.

\section{References}

1. Milsom I, Stewart W, Thüroff J. The prevalence of overactive bladder. Am J Manag Care 2000;6:S565-73.

2. Stewart WF, Van Rooyen JB, Cundiff GW, et al. Prevalence and burden of overactive bladder in the United States. World J Urol 2003;20:327-36.

3. Coyne KS, Sexton CC, Thompson CL, et al. The prevalence of lower urinary tract symptoms (LUTS) in the USA, the UK and Sweden: results from the Epidemiology of LUTS (EpiLUTS) study. BJU Int 2009;104:352-60.

4. Irwin DE, Milsom I, Hunskaar S, et al. Population-Based Survey of Urinary Incontinence, Overactive Bladder, and Other Lower Urinary Tract Symptoms in Five Countries: Results of the EPIC Study. Eur Urol 2006;50:1306-14; discussion 1314-5.

5. Nambiar AK, Bosch R, Cruz F, et al. EAU Guidelines on Assessment and Nonsurgical Management of Urinary Incontinence. Eur Urol 2018;73:596-609.

6. Chapple CR, Cardozo L, Nitti VW, et al. Mirabegron in overactive bladder: A review of efficacy, safety, and tolerability. Neurourol Urodyn 2014;33:17-30. 
7. Cui Y, Zong H, Yang C, et al. The efficacy and safety of mirabegron in treating OAB: a systematic review and meta-analysis of phase III trials. Int Urol Nephrol 2014;46:275-84.

8. Wu T, Duan X, Cao CX, et al. The role of mirabegron in overactive bladder: a systematic review and meta-analysis. Urol Int 2014;93:326-37.

9. Chapple CR, Cruz F, Cardozo L, et al. Safety and Efficacy of Mirabegron: Analysis of a Large Integrated Clinical Trial Database of Patients with Overactive Bladder Receiving Mirabegron, Antimuscarinics, or Placebo. Eur Urol 2020;77:119-28.

Cite this article as: Scandura C, Morgia G, Russo GI. Comment on: Safety and efficacy of mirabegron: analysis of a large integrated clinical trial database of patients with overactive bladder receiving mirabegron, antimuscarinics, or placebo. Transl Androl Urol 2020;9(5):2305-2307. doi:10.21037/tau-20-876
10. Vazquez Roque M, Bouras EP. Epidemiology and management of chronic constipation in elderly patients. Clin Interv Aging 2015;10:919-30.

11. White WB, Siddiqui E, Tat T, et al. Cardiovascular safety of mirabegron: analysis of an integrated clinical trial database of patients with overactive bladder syndrome. J Am Soc Hypertens 2018;12:768-78.e1.

12. Kelleher C, Hakimi Z, Zur R, et al. Efficacy and Tolerability of Mirabegron Compared with Antimuscarinic Monotherapy or Combination Therapies for Overactive Bladder: A Systematic Review and Network Meta-analysis. Eur Urol 2018;74:324-33. 